\title{
Memórias de alunos universitários acerca das práticas avaliativas na educação básica
}

\begin{abstract}
Resumo: O presente artigo objetiva analisar a narrativa escrita de alunos universitários de quatro cursos de licenciatura de uma universidade federal no Triângulo Mineiro, no que diz respeito às suas percepções acerca das práticas avaliativas vivenciadas enquanto alunos da educação básica. Para tanto, foi realizada uma atividade na disciplina Avaliação Educacional, ministrada no segundo semestre de 2018, em que os alunos registram, por meio de tópicos, suas memórias sobre a avaliação na educação básica. Participaram da atividade 50 alunos, os quais realizaram-na em duplas e em trios. Tendo em vista uma maior organização dos registros a partir dos assuntos contemplados, as narrativas foram divididas em duas categorias temáticas: diferentes práticas de avaliação e abuso de poder. Os resultados mostram que a ação de avaliar pode ser ampla, assumindo um caráter diagnóstico processual e contínuo; à medida que, quando relacionada com o abuso de poder, passa a ser uma ferramenta de domínio do professor sobre o aluno. Conclui-se a importância do desenvolvimento de um processo avaliativo a partir de uma perspectiva transformadora, em que a participação do aluno é valorizada, tendo o professor o papel de atuar no mapeamento das dificuldades daquele.
\end{abstract}

Palavras-Chave: Práticas avaliativas na educação básica. Memória. Alunos universitários.

\section{Introdução}

Nos últimos trinta anos, pesquisas acadêmico-científicas sobre as práticas avaliativas escolares vêm constituindo uma importante área de investigação para se refletir o processo de ensino e de aprendizagem na educação básica. Autores como Hoffamn (2009) e Fernandes (2006) evidenciam a importância de uma avaliação para além da ação de se medir os conhecimentos adquiridos pelo aluno.

No âmbito educacional, a avaliação é um fenômeno que se inter-relaciona com as relações estabelecidas em sociedade e com os espaços histórico-culturais. Nesse sentido, o processo avaliativo é determinado por condicionantes históricos, sociais, econômicos, políticos e pedagógicos, a partir de uma dialogicidade com o contexto em que se insere. Avaliar é um processo que envolve conceitos, princípios e valores, e, por isso, não se encontra isento de subjetividade.

Inerente à prática pedagógica em sala de aula, a avaliação ocupa lugar de destaque nas relações entre professores e alunos, podendo contribuir, por exemplo, para o desenvolvimento de situações de
Anelise Martinelli Borges Oliveira Universidade Federal do Triângulo Mineiro

anelise.oliveira@uftm.edu.br Mari Clair Moro Nascimento Universidade Estadual de Londrina mariclairmoro@hotmail.com 
proximidade e empatia, ou até mesmo situações de constrangimento e medo, sobretudo por parte do aluno. Como principal instrumento legitimador do sucesso ou do fracasso na escola, a avaliação está centrada no aproveitamento escolar, cabendo ao professor a tarefa de julgar o rendimento do educando, rendimento esse que se supõe refletir a eficácia do sistema educativo.

$\mathrm{Na}$ perspectiva de que o processo avaliativo pode ocasionar estados e reações diversos, tanto por parte de quem avalia quanto de quem é avaliado, este trabalho tem como objetivo analisar a narrativa escrita de alunos universitários de quatro cursos de licenciatura, de uma universidade federal localizada no Triângulo Mineiro, no que tange às suas memórias sobre as práticas avaliativas vivenciadas enquanto alunos na educação básica.

O trabalho com as memórias dos futuros professores, acerca da avaliação da aprendizagem, teve o intuito de resgatar vivências que os mesmos tiveram nos bancos escolares, uma vez que as aprendizagens obtidas ao longo da vida interferem na construção da identidade docente. (TARDIF, 2002) Assim, para se ter conhecimento sobre as vivências dos licenciandos, foi realizada uma atividade na disciplina Avaliação Educacional, no segundo semestre de 2018, em que participaram cinquenta graduandos. Nessa atividade ${ }^{1}$, além da docente responsável pela disciplina apresentar fundamentos teóricos e práticos das concepções avaliativas, chamou os futuros professores a refletirem sobre o exercício da docência e a estabelecerem mudanças, se necessário, porque "[...] os professores retraduzem sua formação e a adaptam à profissão, eliminando o que lhes parece inutilmente abstrato ou sem relação com a realidade vivida e conservando o que se pode servir-lhes de uma maneira ou de outra." (TARDIF, 2002, p. 53)

Tendo em vista uma maior organização dos registros a partir dos assuntos contemplados, as narrativas foram divididas em duas categorias temáticas: diferentes práticas de avaliação e abuso de poder.

Ao longo do presente estudo, serão realizadas algumas considerações no que tange à questão da memória; posteriormente será feita uma análise acerca das narrativas escritas dos graduandos sobre a memória que possuem da avaliação na educação básica, a partir de um diálogo com autores que abordam a temática da avaliação. 


\section{Memória de avaliação na educação básica: o que dizem os alunos dos cursos de licenciaturas}

Entende-se por memória o processo de (re)atualização dos acontecimentos e das experiências vividas, a qual se desencadeia no presente. A memória do passado se revela no tempo presente, sendo uma (re)criação do passado, como mostra Seixas (2001, p. 42, grifos da autora):

Toda memória é fundamentalmente 'criação do passado': uma reconstrução engajada do passado (muitas vezes subversiva, resgatando a periferia e os marginalizados) e que desempenha um papel fundamental na maneira como os grupos sociais mais heterogêneos apreendem o mundo presente e reconstroem sua identidade, inserindo-se assim nas estratégias de reivindicação por um complexo direito ao reconhecimento.

Enquanto fenômeno mutável, a memória (individual ou coletiva) pode tornar real determinados fatos, à medida que pode modificar outros. De acordo com Pollak (1992), há três elementos principais que constituem a memória: os acontecimentos, as pessoas e os lugares. Os acontecimentos podem ser vividos individualmente, ou, "por tabela", no qual a memória coletiva herdada faz com que o indivíduo sinta parte do acontecimento, mesmo sem ter participado dele. O acontecimento adquire tais proporções que é praticamente impossível afirmar se o indivíduo participou ou não dele. À esse fenômeno, Pollak (1992) chama de projeção; as pessoas, as quais podem ter vivido realmente determinado fato, ou, "por tabela" (se apropriado, por identificação de determinado passado, de um espaço-tempo que não viveu); e, os lugares, em que pessoas se ligam a eles por uma lembrança (infantil, comemorativa, etc.), mesmo que "por tabela"

Além da problemática das projeções, há a questão dos vestígios datados na memória, onde é recordada uma data precisa de determinado acontecimento. Assim, os relatos podem trazer precisão acerca de datas ligadas à vida íntima (como casamento, nascimento/ morte de familiares) em detrimento de datas relacionadas à vida profissional e(ou) pública. De forma contrária, determinados relatos podem conter mais aspectos da vida profissional, de modo que a vida (data) pública se torna vida (data) privada. No entendimento de Pollak (1992), não se pode conceber isso como uma falsificação
(1) Quando no momento de sua realização em sala de aula tal atividade teve o propósito de desencadear nos alunos universitários o repensar sobre as práticas no contexto da escola contemporânea. Devido à riqueza dos resultados da atividade, tevese posteriormente a intenção de transformar em pesquisa o registro dos alunos, resultante neste texto, no sentido de demonstrar à comunidade acadêmica, especialmente aos docentes que atuam na formação inicial para a docência, que rememorar as vivências na educação básica pode proporcionar aos graduandos novas formas de exercer a docência. Nesse sentido, a atividade não foi submetida ao Comitê de Ética.

(2) Esses três elementos constitutivos da memória podem ser fatos concretos ou se tratar de uma projeção/transferência de outros eventos. Como exemplo, Pollak (1992) menciona que na França há certa confusão sobre o que pertenceu à $1^{\mathrm{a}}$ e à $2^{\mathrm{a}}$ guerras mundiais, sendo que, em alguns relatos, ambas se tornam uma grande guerra. No que diz respeito às guerras mundiais, o autor cita ainda a transferência de memória dos pais/familiares para parentes mais novos, onde um determinado tipo de capacete, o qual existiu somente durante a $1^{\mathrm{a}}$ guerra, também foi relatado por pessoas que vivenciaram a $2^{\mathrm{a}}$ guerra. 
do que realmente ocorreu, uma vez que a vida do indivíduo pode ter se reduzido à representação do personagem público.

Portanto, a memória não se refere apenas à vida física do indivíduo, ela é igualmente herdada, sofrendo flutuações em função do momento em que está sendo articulada. Enquanto fenômeno construído social e individualmente, a memória pode se organizar em função das preocupações pessoais e políticas do momento, contribuindo para reforçar sentimentos de identidade e de pertencimento: [...] "a memória é um elemento constituinte do sentimento de identidade, tanto individual como coletiva, na medida em que ela é também um fator extremamente importante do sentimento de continuidade e de coerência de uma pessoa ou de um grupo em sua reconstrução de si." (POLLAK, 1992, p. 204) A memória e o sentimento de identidade "[...] são valores disputados em conflitos sociais e intergrupais, e particularmente em conflitos que opõem grupos políticos diversos." (POLLAK, 1992, p. 205, grifos do autor), pois se tem preocupações - de governos, autoridades, grupos que detém o poder econômico, político, etc. -, sobre quais fatos serão "gravados" na memória de determinada sociedade.

No presente trabalho, interessa os fatos gravados na memória dos alunos licenciandos sobre a forma como foram avaliados na educação básica. Conforme pontuado anteriormente, essas "memórias" foram divididas nas categorias temáticas: diferentes práticas de avaliação e abuso de poder, as quais serão vistas a seguir.

\section{Diferentes práticas de avaliação}

A palavra avaliar deriva do latim, tendo por significado atribuição de mérito e valor ao objeto que se estuda. Assim, avaliação diz respeito à atribuição de um juízo de valor para mapear a qualidade do seu resultado, e, no âmbito escolar, associa-se, de forma simplista, ao ato de medir os conhecimentos apropriados pelo aluno. (KRAEMER, 2005)

A avaliação que acontece em sala de aula se baseia na relação professor e aluno, constituindo de:

[...] uma ação ampla que abrange o cotidiano do fazer pedagógico e cuja energia faz pulsar o planejamento, a proposta pedagógica e a relação entre todos os elementos da ação educativa. Basta pensar que avaliar é agir com base na compreensão do outro, 
para se entender que ela nutre de forma vigorosa todo o trabalho educativo. (HOFFMANN, 2009, p. 17)

A prática avaliativa pressupõe reflexão e questionamento sobre a própria ação docente, levando-se em consideração os sujeitos que se encontram envolvidos nesse processo, e, em especial, o aluno. Considera-se, assim, importante o professor utilizar diversos procedimentos e instrumentos de avaliação, e não somente as provas, no sentido de avaliar o educando nas mais diversas vertentes, pois cada instrumento possibilita ao professor coletar informações diferentes acerca de como está a aprendizagem e o desenvolvimento do educando. Conforme indica Silva (2004, p. 66), "[...] não se justifica o uso apenas de um instrumento avaliativo, pois quanto maior for o seu número, mais tipos de informações poderão ser coletadas, possibilitando uma melhor compreensão e intervenção sobre o objeto avaliativo". Frente ao exposto, fica evidente que a avaliação é o processo por meio do qual o professor faz o mapeamento de como o aluno está aprendendo, coleta que se vale da diversificação de instrumentos avaliativos. No entanto, apenas conhecer como está o aprendizado do aluno não favorece melhorias,

[...] porque o importante é que, de posse dessas constatações, sejam desencadeadas ações de melhorias para os aspectos dificultadores. Diferente disso tende a prevalecer a simples verificação, a encerrar o ato avaliativo no momento em que se faz a identificação dos erros e dos acertos cometidos pelos alunos e seu subsequente registro sob a forma de escores. (NASCIMENTO, 2012, p. 97)

Libâneo (1994) lembra que um dos equívocos da escola brasileira é conceber a avaliação como o ato de se aplicar provas escritas, e atribuir notas aos alunos, a partir de critérios classificatórios, prevalecendo a verificação, ato que se encerra na simples identificação da nota, sem uma tomada de atitude para sanar as dúvidas dos alunos. Reduzida à cobrança do que o discente memorizou, a avaliação é muitas vezes utilizada pelo professor como instrumento de controle:

É verdade que a atitude de dar notas somente com base em provas escritas tem limitações. As provas frequentemente são empregadas apenas para medir capacidade de 
memorização. Os livros didáticos e as tarefas dadas pelos professores estão repletos de exercícios desse tipo. (LIBÂNEO, 1994, p. 200)

Conforme se observa a seguir na narrativa dos alunos licenciandos, alguns pontos positivos da memória da avaliação na educação básica seriam a utilização, pelo professor, de diferentes instrumentos avaliativos e de espaços para além da sala de aula: "Seminários, feiras de ciência e feira literária."; "Participação em atividades extracurriculares."; "Apresentação de trabalhos."; "Atividades dinâmicas, utilizando plataformas digitais."; "Avaliação ao ar livre com acesso ao recurso didático."; "[O professor] passava filmes com animais e dava atividades para relacionar com conceitos dentro da ciência".

A forma pela qual professores realizavam o processo avaliativo também foi pontuada pelos discentes: "Alunos elaboravam as questões e tiravam dúvidas como meio de avaliação."; "Prova de consulta visando o conhecimento e a capacidade do aluno de buscar a informação de maneira eficaz."; "Provas em duplas".

Percebe-se, na primeira narrativa, que a inversão do autor que cria as questões da prova - o aluno e não mais o professor -, foi satisfatória para o aprendizado dos alunos, uma vez que eles próprios foram produtores dos questionamentos e das possíveis respostas, com o auxílio do docente. No que concerne à prova com consulta, subtende-se que pode vir a proporcionar uma maior segurança, caso o aluno se esqueça de algum conteúdo, além de requerer que a partir da consulta ele reestruture sua resposta, ação que pode oportunizar a construção de saberes, ainda no instante da prova. Ambos os relatos evidenciam o aluno como construtor do seu conhecimento.

Em relação ao protagonismo dos alunos na construção do conhecimento, citam-se igualmente as seguintes narrativas: "O que me marcou na aula de ciências foi ver o tipo sanguineo através de práticas em laboratório para o ensino de genética."; "Pesquisa e elaboração de experimentos.". Aqui, atividades de investigação aparecem como necessárias para a aquisição de novos conhecimentos, por meio da interação do sujeito (aluno) com a realidade vivenciada. O educando passa a ser o centro e o educador o auxilia nesse processo. Segundo Demo (2000, p. 85): "Torna-se premente assumir, definitivamente que a melhor maneira de aprender não é escutar aula, mas pesquisar e elaborar com mão própria, sob orientação do professor". 
É interessante assinalar que algumas das narrativas dos alunos destacam como ponto positivo da avaliação: "Conteúdo ensinado coerente com a prova."; "Quando seus estudos são recompensados.". O primeiro relato traz a ideia de que nem sempre o assunto cobrado na prova condiz com o ensino, o que é uma incongruência, pois subtende-se que todo professor, em sua prática pedagógica, deveria solicitar, nos instrumentos avaliativos, os conteúdos trabalhados em sala de aula. Já o segundo relato expõe acerca de recompensas no estudo, uma prática que, se vinculada às premiações, induz o aluno a estudar para obter algo externo como reconhecimento de ser inteligente ou esforçado, ou até mesmo o ganho de objetos, reforços que induzem o educando a estudar para tirar nota e não para a aquisição de conhecimentos.

A devolutiva dos professores com relação à prova foi igualmente abordada de forma positiva pelos alunos, especialmente, nas seguintes memórias: "Após entrega da prova o professor pede a correção das questões incorretas valendo ponto - bom para aprender o certo e não apenas esquecer depois da prova."; "Professores corrigindo oralmente questões de uma prova.". Essas narrativas sugerem a importância do professor compreender os erros nos instrumentos avaliativos para a superação das dificuldades dos discentes, e assim "[...] proporcionar um feedback de elevada qualidade, que ajude a melhorar a aprendizagem dos alunos, nomeadamente mediante processos de autorregulação, de auto avaliação e de autocontrole." (FERNANDES, 2006, p. 26, grifo do autor) Ao receber um feedback adequado, no que tange a seus progressos e dificuldades, o aluno passa a atribuir sentido e significado no que aprende.

Com relação à realização dos instrumentos avaliativos propostos pelo professor, aparecem as seguintes narrativas: "O alivio após a prova."; "O choro após a prova."; "Pressão psicológica por boas notas."; "Medo de decepcionar os pais."; "As avaliações sempre foram uma questão de ansiedade para mim, com provas extensas e complicadas."; "Avaliações orais para pessoas tímidas deixam traumas.". Os relatos possuem um ponto em comum: a ideia de que a avaliação pode gerar inquietação no aluno. Também revelam que a situação de prova gera, muitas vezes, efeitos negativos, como por exemplo a cobrança pessoal/familiar/social, a competição e o medo diante da possibilidade de fracasso. De fato, a situação de prova traz preocupação por parte do discente, seja em momento anterior à sua realização (no que tange à preparação, ao planejamento dos estu- 
dos), seja durante (no que diz respeito à obrigação de se lembrar do conteúdo) ou mesmo posteriormente (em que se tem incerteza do desempenho). Como pontua Gonzaga e demais autores (2016, p. 78), tal prática avaliativa pode ocasionar ansiedade, uma vez que:

[...] com a aproximação de uma prova, o indivíduo está preocupado com as demandas, possibilidades e constrangimentos relacionados a ela e pensa em como se preparar e regular os sentimentos e emoções associadas com a avaliação negativa. A incerteza dos resultados é alta, nesta fase, podendo ser experimentada emoções ameaçadoras e/ou desafiadoras.

Dado que a ansiedade é um dos problemas do século XXI (ANDRADE et al., 2019), é importante, no contexto escolar, a utilização de estratégias que possam diagnosticar situações estressoras e seu posterior enfretamento, a partir de um diálogo com outras áreas do conhecimento, especialmente com a área das ciências da saúde. Nesse sentido, faz-se fundamental uma mudança de paradigma quanto à concepção, muitas vezes simplista, que se tem da avaliação da aprendizagem, porque esse processo

[...] pressupõe uma partilha de responsabilidades entre alunos e professores em matéria de avaliação e regulação das aprendizagens. Obviamente, os professores terão um papel que é, ou deve ser, preponderante em aspectos como a organização e a distribuição do processo de feedback, enquanto os alunos terão uma evidente preponderância no desenvolvimento dos processos que se referem à auto-avaliação e à auto-regulação de suas aprendizagens. (FERNANDES, 2009, p. 60)

Como fator negativo, as memórias dos licenciandos, sobre a realização de provas bem como sobre a atribuição de notas na educação básica, foram assim expostas:

'O acúmulo de provas de diferentes matérias.'; 'Muitas questões para pouco tempo.'; 'No primeiro ano do Ensino Médio eu era avaliada de quatro maneiras, duas provas de testes e duas provas dissertativas de uma mesma disciplina, e isso era muito maçante.'; 'Caráter competitivo das avaliações.'; 'Na escola, a nota dos alunos era em forma de letras, sendo I-Irregular, R-Regular, B-Bom e M- Muito Bom, e com isso nunca sabiamos qual era a nossa nota específica'. 
As memórias anteriores evidenciam a avaliação como processo simplista de classificação do aluno. Isso vai ao encontro das palavras de Libâneo (1994, p. 95), quando afirma que a avaliação é muitas vezes resumida à "[...] realização de provas e atribuição de notas", cumprindo função "[...] de controle em relação as quais se recorrem a instrumentos de verificação do rendimento escolar." Os escritos também apontam a prova como um dispositivo de disputa e competitividade, características que, segundo Libâneo (2013), estão presentes na escola brasileira desde a década de 1990, tendo em vista que as escolas possuem metas a serem atingidas, e, competências a serem desenvolvidas nos alunos, para que estes sejam preparados a responder as avaliações em larga escala que medem o conhecimento ${ }^{3}$.

A avaliação, enquanto processo que compõe a prática docente precisa ser pensada como uma ação formalmente sistematizada e organizada, associada ao contexto social vivido pelos agentes do espaço escolar. Ao refletir os valores e crenças contidas na sociedade, a avaliação expressa "[...] um juízo de valor, uma dada concepção de mundo e de educação, e por isso vem impregnada de um olhar absolutamente intencional que revela quem é o educador quando interpreta os eventos da cena pedagógica." (SORDI, 2001, p. 173) Devido a isso, a prática avaliativa não acontece em períodos isolados do trabalho docente, mas se faz presente durante todo o ano letivo:

A avaliação escolar é um meio e não um fim em si mesma; está delimitada por uma determinada teoria e por uma determinada prática pedagógica. Ela não ocorre num vazio conceitual, mas está dimensionada por um modelo teórico de sociedade, de homem, de educação e, consequentemente, de ensino e de aprendizagem, expresso na teoria e na prática pedagógica. (CALDEIRA, 2000, p. 122)

Assim, é importante que a avaliação esteja imbuída de sentido e significado para o aluno. Na contramão dessa ideia, estão as seguintes afirmações dos graduandos:

'Cobrança de conteúdo incoerente com o conteúdo ministrado em sala de aula.'; '[o professor] solicitou atividades desnecessárias, nas quais só se copiava matéria em forma de resumo.; 'Ler um texto complexo e responder. Respondemos com trechos de texto que não entendemos e por fim só recebemos o visto. O professor não deu nenhuma explicação do sentido daquela atividade'.
(3) Como exemplo, pode-se citar o Saeb (Sistema Nacional de Avaliação da Educação Básica), que é um conjunto de avaliações externas que tem por objetivo realizar um diagnóstico da educação básica brasileira bem como dos fatores que podem interferir no desempenho do aluno. Informações disponíveis em: http:// portal.inep.gov.br/educacaobasica/saeb. Acesso em: 17 jun. 2020 
Depreende-se, pelas frases anteriores, a abordagem de conteúdos em sala de aula sem um objetivo definido, o qual pudesse vir a agregar ao conhecimento do discente. Tais atividades geram desinteresse e desmotivação no aluno, o qual passa a frequentar a escola, ou mesmo a aula de determinado professor, muitas vezes, por obrigação, fato que pode contribuir para o fracasso da aprendizagem e até mesmo para a evasão escolar. A avaliação precisa ter um propósito e fazer sentido para o aluno. Como mesmo afirma Moreto (2008, p. 87): "[...] se tivermos que elaborar provas, que sejam bem feitas, atingindo seu real objetivo.", porque não há problemas em utilizar esse instrumento avaliativo, desde que seus resultados sejam interpretados pelo professor, para ajuste nas suas práticas de ensino e, pelo aluno, para reorganização do próprio percurso de aprendizagem. Assim, aluno e professor são protagonistas ao se efetivar o ato de avaliar. No entanto, cabe lembrar que a aprendizagem é construída nas relações em sala de aula, sendo o professor, o responsável por proporcionar condições para tal.

\section{Abuso de poder}

A escola se configura como uma instituição disciplinar, em que o controle sobre os corpos - especialmente os dos alunos -, acontece por meio da regulação do tempo, espaço e comportamento. A rotina pré-determinada da escola, com horários fixos - entrada e saída, aulas, intervalo etc. - é estabelecida para que as atividades aconteçam de forma previsível, em consonância com as regulamentações da escola, e não saiam do que se considera como esperado. A lógica disciplinar se estrutura em uma necessidade de vigilância por parte das autoridades escolares, e para isso, mecanismos de controle e punição são disseminados no cotidiano do estabelecimento de ensino. Cabe lembrar que o processo de controle sobre o indivíduo é característica de muitos tipos de instituições - a prisão, a clínica, a fábrica, a família, a universidade, o próprio Estado - como mesmo assinala Foucault (2009). Nessa perspectiva, as práticas escolares estão vinculadas às relações de poder e a avaliação não está alheia a isso.

O poder disciplinar, segundo Foucault (2009, p. 164):

[...] é um poder modesto, desconfiado, que funciona a modo de uma economia calculada, mas permanente [...] O sucesso do poder disciplinar se deve sem dúvida ao uso de instrumentos 
simples: o olhar hierárquico, a sansão normalizadora e sua combinação num procedimento que lhe é específico, o exame.

Com efeito, não são raros os casos em que a avaliação é utilizada como instrumento de punição. Isso pode ser visto a seguir, nas narrativas dos graduandos:

'Professor descontou a raiva devido a uma reclamação, resultando em anulação da prova e aplicação de uma nova prova com nível extremamente elevado.; 'Professor autoritário, que tirava ponto de quem não acertava um exercício passado na lousa.'; 'Avaliação surpresa para fins de punição!

Em todas as afirmações, fica notório que a ação punitiva do professor vem acompanhada da legitimação da manutenção do poder, no sentido de mostrar aos alunos sua autoridade absoluta. Além disso, a não obtenção do que é idealizado pelo professor (o acerto do aluno e a disciplina) pode vir acompanhada de consequências, como por exemplo, a retirada de pontos do discente que errou determinada atividade, conforme é verificado no segundo relato. Já o erro do aluno, aparece, de forma negativa, associado à incompetência e ao fracasso, e não como oportunidade de superação e possibilidade do aluno vir a aprender: "Aparentemente, aprender é acertar, é ajustar-se ao exposto pelo professor, ou pelo material instrucional, reproduzindo conhecimentos. Não há espaço ou tempo para o erro, não há permissão para os enganos, malogros ou falhas." (NASCIMENTO, 2012, p. 41)

A atribuição de notas - ou sua retirada - é um exercício de poder: "[...] o prazer de dar nota está, antes de tudo, em saborear um certo poder. Por definição, pronunciar um julgamento de valor é - pelo menos implicitamente - considerar-se como detentor da norma do bom, do verdadeiro, etc." (BARLOW, 2006, p. 40)

A prática avaliativa também pode estar ligada a situações de constrangimento. De acordo com os licenciandos:

'O professor reuniu todos os alunos que ficaram de exame no auditório e zoou dos alunos por isso, expondo-os ao ridículo.'; ' Exposição das falhas do aluno (notas baixas)'.; ' [O professor] Falar notas da prova em voz alta' 'Anotar nomes no quadro.'; 'Professor debochou de mim por conta de uma leitura em voz alta em que eu não sabia ler algarismos romanos.'; 'Tive uma professora de inglês que só deixava a gente ir ao banheiro ou beber água se pedisse em 
inglês.; 'O professor tomava tabuada dos alunos para eles entrarem na sala:; 'Humithação por não saber responder e por demorar a terminar a prova'.

A análise das narrativas anteriores permite atentar para alguns tipos de abusos - humilhação, discriminação, arbitrariedade e violência psicológica -, em que decisões unilaterais são tomadas nas relações estabelecidas em sala de aula. Tais decisões não concebem a avaliação como um processo para aquisição de conhecimento, mas sim como um exercício do poder em si, podendo ter consequências desastrosas para os alunos, dadas as circunstâncias muitas vezes vergonhosas e até traumáticas. Assim, a postura do professor vai contra a concepção de avaliação como processo interativo, dialógico, cujo objetivo é a construção de conhecimento pelo aluno e a reorganização das práticas docentes para favorecer a superação do erro, pois o processo avaliativo só tem sentido quando promove a melhoria do status do conhecimento do aluno.

Uma vez mais, as narrativas dos licenciandos evidenciam a idealização em se obter dos alunos certas atitudes consideradas "legítimas" (o cumprimento de rituais determinados pelo professor/escola/sistema de ensino) e a repreensão por não atingirem tal idealização - como por exemplo a exposição desses alunos, seja fisicamente em um local específico, como o auditório, seja com o nome escrito no quadro. A última narrativa deixa subentender que o aluno foi discriminado por não conseguir finalizar a prova no tempo determinado, ou seja, por não cumprir o ritual de avaliação estabelecido pelo professor, uma atitude que desconsidera as especificidades dos sujeitos que compõem o universo da sala de aula.

Para Barlow (2006, p. 153), a avaliação escolar pode vir a ser um ato de segregação, manifestando-se de diversas formas: "[...] seja pela proclamação pública dos resultados (notas cifradas, classificação por ordem de mérito, "quadro de honra", etc.); seja por sinais distintivos (cruzes, fitas, etc.); seja, enfim, concedendo nas salas de aula "lugares de honra" para os melhores alunos." Isso pode ser visualizado especialmente na assertiva de um graduando ao revelar que o "Professor escrevia no quadro de notícias da escola os nomes dos alunos que tiravam notas boas". Na concepção de classificar em mais ou menos inteligentes, bons ou maus alunos, a avaliação acontece "[...] sempre com a intenção de corrigir, penalizar, sancionar, qualificar." (ÁLVAREZ MÉNDEZ, 2002, p. 64), sendo realizada a serviço dos que se encaixam nas características do aluno ideal, descartando 
qualquer possibilidade do olhar para ajustes nas práticas de ensino, após a análise e interpretação das dificuldades identificadas nos instrumentos ou procedimentos avaliativos.

A avaliação ainda pode servir como instrumento de vingança, conforme exposto:

Uma vez, um professor do Ensino Médio formulou uma prova muito difícil de química. Ele assustou os alunos durante uma semana inteira, dizendo que não iríamos conseguir responder a prova e quando estávamos realizando a avaliação, ele ria o tempo todo dos alunos, mandando que entregássemos a prova e desistíssemos. Isso me marcou, pois ninguém conseguiu ir bem, apesar de saber a matéria.

O relato anterior sugere a intenção do professor em utilizar a prova como represália, provavelmente contra algum comportamento da turma. Nesse ponto, pode-se lembrar de Vasconcellos (2000, p. 37), quando reflete: "[...] de instrumento de análise do processo educacional, a avaliação tornou-se instrumento de dominação, de controle, de seleção social, de discriminação, de repressão, adquirindo até um caráter passional de vingança, de 'acerto de contas'”. $\mathrm{Na}$ fala do graduando, percebe-se que o professor faz ameaças aos alunos não apenas em momentos anteriores à prova, como também no ato de sua realização, com o intuito de desmotivá-los e desencorajá-los a realizá-la com sucesso. Nota-se com isso uma sensação de prazer do professor, sobretudo quando o graduando diz "[... ele ria o tempo todo dos alunos, mandando que entregássemos a prova e desistíssemos". A pressão psicológica, tendo por objetivo o fracasso dos alunos, fica clara no trecho "[...] ninguém conseguiu ir bem, apesar de saber a matéria". O relato do licenciando aponta na contramão do que se acredita ser o papel do professor enquanto elemento mediador entre aluno e conhecimento, no que diz respeito à aprendizagem a serviço da humanização e da emancipação.

Os licenciandos também lembraram de algumas situações envolvendo agressão física e agressão verbal enquanto alunos na Educação Básica: "Estresse desnecessário por parte do professor, resultando em desacato verbal com aluno por ações simplórias."; "Professor jogou o caderno da aluna no chão e ficou falando em alto e bom som que ela era burra, etc."; "Castigo atrás da porta."; "Cantinho do castigo." Tais memórias exemplificam a manifestação de abuso de poder exercido pelo professor. O castigo físico aparece como técnica de 
(4) Exemplo disso é a própria legislação, em especial o Estatuto da Criança e do Adolescente (ECA), implantado em 1990, cuja finalidade é a proteção integral da criança e do adolescente.

(5) Esse número foi conseguido durante conversa informal da professora com os alunos que realizaram a atividade. controle, de disciplinarização dos corpos, visando o adestramento de alunos cujas atitudes não estavam condizentes com as normas do professor, da escola, e/ou do sistema de ensino. Para Foucault (2009, p. 143), o poder disciplinar: "[...] em vez de se apropriar e de retirar, tem como função maior "adestrar": ou sem dúvida adestrar para retirar e se apropriar ainda mais e melhor. Ele não amarra as forças para reduzi-las; procura ligá-las para multiplicá-las e utilizá-las num todo".

As memórias anteriores trazem exemplos de situações vexatórias vividas pelos alunos, em que estes são humilhados e ridicularizados perante os demais. Em todas as memórias são verificadas situações de bullying realizadas pelo professor. Aqui, o termo bullying se refere "[...] à exposição repetida a ações propositais que ferem ou prejudicam o indivíduo, caracterizando-se, principalmente, pela disparidade de poder entre os pares, de modo que uma pessoa é dominada por outra." (CALBO et al., 2009, p. 74) Ainda segundo esses autores, o bullying na escola é um "estressor social crônico", podendo desencadear na vítima efeitos como prejuízos no desempenho escolar, comportamento antissocial, baixa autoestima, estresse, ansiedade, depressão, e até mesmo tentativa de autoextermínio. (CALBO et al., 2009)

Em se tratando da regulação dos corpos e dos castigos disciplinares na temporalidade, pesquisa da área da História da Educação (VAGO, 2002) atesta que em décadas e séculos anteriores, as punições infligidas aos alunos eram mais severas, ao se fazer análise comparativa com os dias atuais ${ }^{4}$. No entanto, as memórias dos graduandos dos cursos de licenciatura permitem identificar que o poder disciplinar - e suas formas de punição - ainda está presente atualmente nas escolas, ao levar em consideração que a maior parte desses licenciandos possuem idade de 20 a 25 anos $^{5} \mathrm{e}$ concluíram a educação básica nos últimos anos.

A avaliação como uma prática reduzida à punição e à recompensa tem por objetivo moldar os sujeitos conforme o desejável pelo professor. "Valendo-se dessas duas ações, todo um processo de controle é desencadeado, evidenciando-se nas comparações, diferenciações, hierarquizações, exclusões ou inclusões realizadas, no intuito de homogeneizar formas de pensar e agir." (NASCIMENTO, 2012, p. 54) Um processo avaliativo excludente que desencadeia a competitividade entre os alunos, muito mais do que a ajuda para auxiliar o outro a progredir no conhecimento. 


\section{Considerações finais}

A avaliação é um instrumento pedagógico inerente à prática do professor. Para além da concepção reducionista que visa a atribuição de notas e classificação do aluno, a avaliação precisa ser pensada como um processo, cuja finalidade é a construção de conhecimento pelo aluno, um ser ativo e dinâmico e a reorganização das práticas docentes, a partir da análise dos resultados obtidos no instrumental avaliativo.

A análise das memórias dos graduandos sobre a avaliação na educação básica mostrou que a prática avaliativa pode estar relacionada com o abuso de poder quando passa a ser uma ferramenta de domínio do professor sobre o aluno. Assim, a avaliação surge como ameaça, vingança, segregação e até mesmo humilhação, despertando estados emocionais de vergonha, ansiedade e medo, por exemplo. Tal concepção de avaliação fica evidente em algumas narrativas, quando o professor, ao fazer uso do poder disciplinador, discrimina e/ou impede a ocorrência de falhas dos alunos por meio de punições diversas - agressão verbal e castigo físico, por exemplo.

Em contrapartida, as narrativas dos licenciandos também revelaram que a ação de avaliar pode ser ampla, assumindo um caráter diagnóstico processual e contínuo. Isso pôde ser constatado nas narrativas em que o professor não utiliza apenas a prova como único instrumento avaliativo, mas outros como o uso de filmes, feiras pedagógicas e seminários. Até mesmo com relação à prova escrita, constatou-se que a mudança da forma tradicional de aplicação - com consulta, em duplas - foi vista como positiva para os alunos.

Acredita-se que cabe ao professor utilizar a avaliação para constatar dificuldades e progressos na aprendizagem do aluno, articulando-se ao processo educativo, social e político vivenciado em sociedade. A partir de uma perspectiva transformadora, a avaliação passa a considerar e valorizar a participação do aluno, tendo o professor o papel de atuar para mapear as dificuldades, ação que requer atenção para suas incompreensões, portanto, para os erros. Nesse sentido, os erros são reconhecidos como uma aprendizagem em potencial, a ser construída mediante a diversificação nas estratégias de ensino, o que demanda que o professor ensine o mesmo conteúdo e diversas formas, considerando a diversidade dos alunos existentes na sala de aula e, sobretudo, suas especificidades. 


\title{
University students' memories of evaluative practices in basic education
}

\begin{abstract}
This article aims to analyze the written narrative of university students from four undergraduate courses at a federal university in Triângulo Mineiro, with regard to their perceptions about the evaluative practices experienced as students of basic education. To this end, an activity was carried out in the Educational Assessment discipline, taught in the second semester of 2018, in which students recorded, through topics, their memories about assessment in basic education. Fifty students participated in the activity, which were carried out in pairs and in trios. In view of a greater organization of records based on the subjects covered, the narratives were divided into two thematic categories: different assessment practices and abuse of power. The results show that the action of evaluating can be broad, assuming a procedural and continuous diagnostic character; to the extent that, when related to the abuse of power, it becomes a tool for teacher control over the student. We conclude the importance of developing an evaluation process from a transforming perspective, in which the student's participation is valued, with the teacher having the role of mapping the student's difficulties.
\end{abstract}

Keywords: Evaluative practices in basic education. Memory. University students.

\section{Memorias de estudiantes universitarios sobre prácticas evaluativas en educación básica}

\begin{abstract}
Resumen: Este artículo tiene como objetivo analizar la narrativa escrita de estudiantes universitarios de cuatro cursos de pregrado en una universidad federal en Triângulo Mineiro, con respecto a sus percepciones sobre las prácticas evaluativas experimentadas como estudiantes de educación básica. Con este fin, se realizó una actividad en la disciplina de Evaluación Educativa, impartida en el segundo semestre de 2018, en la que los estudiantes registraron, a través de temas, sus recuerdos sobre la evaluación en educación básica. Cincuenta estudiantes participaron en la actividad, que se llevó a cabo en parejas y en tríos. En vista de una mayor organización de registros basados en los temas tratados, las narraciones se dividieron en dos categorías temáticas: diferentes prácticas de evaluación y abuso de poder. Los resultados muestran que la acción de evaluar puede ser amplia, asumiendo un carácter diagnóstico continuo y de procedimiento; en la medida en que, cuando se relaciona con el abuso de poder, se convierte en una herramienta para el control del maestro sobre el alumno. Llegamos a la conclusión de la importancia de desarrollar un proceso de evaluación desde una perspectiva transformadora, en la que se valore la participación del alumno, y el profesor tenga la función de mapear las dificultades del alumno.
\end{abstract}

Palabras-clave: Prácticas evaluativas en educación básica. Memoria. Estudiantes universitarios.

\section{Referências}

ÁLVAREZ MÉNDEZ, Juan Manuel. Avaliar para conhecer, examinar para excluir. Porto Alegre: Artmed, 2002. 
ANDRADE, João Vitor et al. Ansiedade: um dos problemas do século XXI. Revista de Saúde ReAGES, Paripiranga, v. 2, n. 4, p. 34-39, jul. 2019.

BARLOW, Michel. Avaliação escolar: mitos e realidades. Tradução Fátima Murad. Porto Alegre: Artmed, 2006.

BRASIL. Lei no 8.069, de 13 de julho de 1990. Dispõe sobre o Estatuto da Criança e do Adolescente e dá outras providências. Diário Oficial da União, Poder Legislativo, Brasília, DF, 16 jul.1990. Disponível em: http://www.planalto.gov.br/ccivil_03/leis/18069.htm. Acesso em: 17 jun. 2020.

BRASIL. Ministério da Educação. Instituto Nacional de Estudos e Pesquisas Educacionais Anísio Teixeira. Saeb. Disponível em:http:// portal.inep.gov.br/educacao-basica/saeb. Acesso em: 17 jun. 2020.

CALBO, Adriano Severo et al. Bullying na escola: comportamento agressivo, vitimização e conduta pró-social entre pares. Contextos Clínicos, São Leopoldo, v. 2, n. 2, p. 73-80, jul./dez. 2009.

CALDEIRA, Ana Salgueiro. Ressignificando a avaliação escolar. In: CALDEIRA, Ana Salgueiro. Comissão permanente de avaliação institucional: UFMG-PAIUB. Belo Horizonte: UFMG, 2000.

DEMO, Pedro. Saber pensar. São Paulo: Cortez, v. 6, 2000.

FERNANDES, Domingos. Avaliação, aprendizagens e currículo: Para uma articulação entre investigação, formação e práticas. In: BARBOSA, Raquel Lazzari Leite (org.). Formação de educadores: Artes e técnicas Ciências e políticas. São Paulo: Ed. UNESP, 2006.

FERNANDES, Domingos.. Avaliar para aprender: fundamentos práticas e políticas. São Paulo: Ed. UNESP, 2009.

FOUCAULT, Michel. Vigiar e punir: nascimento da prisão. Trad. Raquel Ramalhete. 36. ed. Petrópolis: Vozes, 2009.

GONZAGA, Luiz Ricardo Vieira et al. Ansiedade de provas em estudantes do ensino médio. Psicologia Argumento, Curitiba, v. 34, n. 84, p.76-88, jan./mar. 2016.

HOFFAMN, Jussara Maria Lerch. Avaliar para promover: as setas do caminho. Porto Alegre: Mediação, 2009.

KRAEMER, Maria Elisabeth Pereira. Avaliação da aprendizagem como construção do saber. In: COLÓQUIO INTERNACIONAL SOBRE GESTÃO UNIVERSITÁRIA DA AMÉRICA DO SUL, 2005, Mar del Plata, Argentina. Anais [...] Mar del Plata: Universidade Nacional de Mar del Plata, 2005, p. 1-16.

LIBÂNEO, Carlos. Didática. 34 ed. São Paulo: Cortez, 1994.

LIBÂNEO, Carlos. Adeus professor, adeus professora? A identidade do professor na contemporaneidade. In: ENCONTRO NACIONAL DAS LICENCIATURAS, 4.; SEMINÁRIO NACIONAL DO PIBID, 3., 2013, Uberaba, Minas Gerais. Anais [...] Uberaba: UFTM, 2013. p. 1-17. 
MORETO, Vasco Pedro. Prova: um momento privilegiado de estudo, não um acerto de contas. 8. ed. Rio de Janeiro: Lamparina, 2008.

NASCIMENTO, Mari Clair Moro. Avaliação da aprendizagem: repercussões de modelos pedagógicos nas concepções docentes. 2012. Dissertação (Mestrado em Educação) - Universidade Estadual de Londrina, Londrina, 2012.

POLLAK, Michael. Memória e identidade social. Tradução Monique Augras. Revista Estudos Históricos, Rio de Janeiro, v. 5, n. 10, p. 200-215, 1992 .

SEIXAS, Jacy Alves. Percursos de memórias em terras de história: problemáticas atuais. In: BRESCIANI, Stella; NAXARA, Márcia (org.). Memória e (res) sentimento: indagações sobre uma questão sensível. Campinas: EdUnicamp, 2001.

SILVA, Janssen, Felipe da. Avaliação na perspectiva formativa-reguladora: pressupostos teóricos e práticos. Porto Alegre: Mediação, 2004.

SORDI, Mara Regina de. Alternativas propositivas no campo da avaliação: por que não? In: CASTANHO, Sérgio; CASTANHO, Maria Eugênia (org.). Temas e textos em metodologia do Ensino Superior. Campinas: Papirus, 2001.

TARDIF, Maurice. Saberes docentes e formação profissional. Petrópolis: Vozes, 2002.

VAGO, Tarcísio Mauro. Cultura escolar cultivo de corpos: Educação Physica e Gymnastica como práticas constitutivas dos corpos de crianças no ensino público primário de Belo Horizonte (1906-1920). Bragança Paulista: EDUSF, 2002.

VASCONCELLOS, Celso. Avaliação: concepção dialética-libertadora. 11. ed. São Paulo: Libertad, 2000.

Submetido em: 17/03/2020

Aceito em: 30/06/2020 